ble to oxacillin and other antibiotics tested. The patient's symptoms resolved and the follow-up period was two months.

Both adolescents had no history of diabetes, smoking, sexual activity, or corticosteroid/contraceptive use. The age of menarche in both girls was 11 years. Predisposing factors for mastitis and breast abscess include skin lesions, mammary duct ectasia, trauma related to sexual foreplay, nipple piercing, and shaving or plucking periareolar hair [3,4]. None of these factors was identified in the cases described. Breast malignancy, tuberculosis, and protozoal and fungal infections are differential diagnoses for mastitis [3].

In both cases, management with oral antibiotic therapy and ultrasound-guided needle aspiration was successful. Surgical drainage should be reserved for unresolved cases following aspiration. This is especially valid for adolescents as surgery may affect the breast bud, resulting in impaired breast development [3].

\section{Conflict of interest}

The author has no conflicts of interest.

\section{References}

[1] Dixon JM. Breast infection. BMJ 2013;347:f3291.

[2] Stricker T, Navratil F, Forster I, Hürlimann R, Sennhauser FH. Nonpuerperal mastitis in adolescents. J Pediatr 2006;148(2):278-81.

[3] Greydanus DE, Matytsina L, Gains M. Breast disorders in children and adolescents. Prim Care 2006;33(2):455-502.

[4] Templeman C, Hertweck SP. Breast disorders in the pediatric and adolescent patient. Obstet Gynecol Clin North Am 2000;27(1):19-34.

\title{
A call to action for evidence-based safer conception interventions for HIV-affected couples desiring children in Sub-Saharan Africa
}

\author{
Okeoma Mmeje ${ }^{\mathrm{a}, *}$, Marita G. Titler ${ }^{\mathrm{b}}$, Vanessa K. Dalton ${ }^{\mathrm{a}}$ \\ a Department of Obstetrics and Gynecology, Medical School, University of Michigan, Ann Arbor, MI, USA \\ b Division of Systems Leadership and Effectiveness Science, School of Nursing, University of Michigan, Ann Arbor, MI, USA
}

\section{A R T I C L E I N F O}

Article history:

Received 24 July 2014

Accepted 16 September 2014

\section{Keywords:}

Childbearing desires

HIV prevention

HIV-serodiscordant couples

Implementation science

Reproductive justice

Safer conception

Sub-Saharan Africa
In support of the reproductive rights and promotion of reproductive justice for HIV-affected couples desiring children, implementation studies are needed to guide the integration of evidence-based interventions in Sub-Saharan Africa. HIV-affected couples desiring children in this region need equitable access to assisted reproductive services (e.g. vaginal insemination, sperm washing with intrauterine insemination, and in vitro fertilization) as components of HIV prevention interventions. Inadequate action to address the reproductive priorities of HIV-affected couples may thwart HIV prevention interventions because couples knowingly risk sexual and perinatal HIV to fulfill their reproductive goals [1]. The present article calls for a shift in the global perspective to address the reproductive desires of individuals and couples affected by HIV.

In Sub-Saharan Africa, HIV-affected couples desiring children are counseled to limit unprotected intercourse to the peak fertile period to limit HIV exposure. Pre-exposure prophylaxis is recommended in

\footnotetext{
* Corresponding author at: Department of Obstetrics and Gynecology, University of Michigan, L4100 Women's Hospital, 1500 East Medical Center Drive, Ann Arbor, Michigan 48109, USA. Tel.: +1 734972 4843; fax: +1 7346479727.

E-mail address: ommeje@umich.edu (O. Mmeje).
}

high-risk partnerships [2], but is not readily available in low-resource settings. In middle- and high-resource countries, HIV-affected couples desiring children have greater options for assisted reproductive services [3,4] and greater access to pre-exposure prophylaxis [5], which may allow couples to conceive while limiting the risk of HIV transmission to their uninfected partner and child (Box 1).

Box 1

Studies demonstrating the efficacy of safer conception methods for HIV-affected couples.

- Treatment of the HIV-infected partner as prevention [6].

- Pre-exposure prophylaxis $[5,7]$.

- Voluntary male medical circumcision [8-10].

- Sperm washing with intrauterine insemination [11,12].

- In vitro fertilization, intracytoplasmic sperm injection $[13,14,15]$.

We should seek to achieve equitable options and access to assisted reproductive services for HIV-serodiscordant couples desiring children in Sub-Saharan Africa, particularly in communities with a high prevalence of HIV and cultures where social identity and value are inextricably linked to reproduction.

Traditionally, "family planning" has referred mainly to contraception and safe abortion. However, it should also embrace a reproductive justice framework that addresses each individual's reproductive need across their life cycle [16]. For HIV-affected couples, this includes access to safer conception education, counseling, and clinical services as components of HIV prevention interventions. Access and provision of safer conception services is an innovative approach to HIV prevention that challenges the status quo and addresses the needs of a critical at-risk population. Implementation studies evaluating safer conception services in Sub-Saharan Africa will highlight the 
barriers and facilitators that may affect the integration and scale-up of evidence-based safer conception programs from high-resource countries. Furthermore, these implementation studies will identify the adaptable program components to ensure cost-effective and sustainable services in low-resource settings. From a reproductive justice perspective, HIV prevention programs should include accessible safer conception services for HIV-affected couples. Financial support needed to achieve this goal may require commitment from foundations and national and global organizations to strengthen HIV prevention efforts and assure the reproductive rights of HIV-affected couples.

\section{Conflict of interest}

OM has been a paid consultant for the World Health Organization. VKD has been a paid consultant for Bayer Healthcare Pharmaceuticals and the University of California, San Francisco.

\section{References}

[1] Brubaker S, Bukusi E, Odoyo J, Okumu A, Cohen CR. Pregnancy and HIV transmission among HIV-discordant couples in clinical trials in Kisumu, Kenya. HIV Med 2011;12(5):316-21.

[2] World Health Organization. Guidance on oral pre-exposure prophylaxis (PrEP) for serodiscordant coupes, men and transgender women who have sex with men at high risk of HIV. Geneva: WHO; 2012. http://www.who.int/hiv/pub/ guidance_prep/en/.

[3] Chadwick RJ, Mantell JE, Moodley J, Harries J, Zweigenthal V, Cooper D. Safer conception interventions for HIV-affected couples: implications for resource constrained settings. Top Antivir Med 2011;19(4):148-55

[4] Moragianni VA. Why are we still, 20 years later, depriving HIV-serodiscordant couples of equal access to fertility care? Fertil Steril 2014;102(2):352-3.
[5] Baeten JM, Donnell D, Ndase P, Mugo NR, Campbell J, Wangisi J, et al. Antiretroviral prophylaxis for HIV prevention in heterosexual men and women. $\mathrm{N}$ Engl J Med 2012;367(5):399-410.

[6] Cohen MS, Chen YQ, McCauley M, Gamble T, Hosseinipou MC, Kumarasamy N, et al. Prevention of HIV-1 infection with early antiretroviral therapy. N Engl J Med 2011;365(6):493-505.

[7] Vernazza PL, Graf I, Sonnenberg-Schwan U, Geit M, Meurer A. Preexposure prophylaxis and timed intercourse for HIV-discordant couples willing to conceive a child. AIDS 2011;25(16):2005-8.

[8] Auvert B, Taljaard D, Lagarde E, Sobngwi-Tambekou J, Sitta R, Puren A. Randomized, controlled intervention trial of male circumcision for reduction of HIV infection risk: the ANRS 1265 trial. PLoS Med 2005;2(11):e298.

[9] Bailey RC, Moses S, Parker CB, Agot K, Maclean I, Krieger JN, et al. Male circumcision for HIV prevention in young men in Kisumu, Kenya: a randomised controlled trial. Lancet 2007;369(9562):643-56.

[10] Gray RH, Kigozi G, Serwadda D, Makumbi F, Watya S, Nalugoda F, et al. Male circumcision for HIV prevention in men in Rakai, Uganda: a randomized trial. Lancet 2007;369(9562):657-66

[11] Semprini AE, Levi-Setti P, Bozzo M, Ravizza M, Taglioretti A, Sulpizio P, et al. Insemination of HIV-negative women with processed semen of HIV-positive partners. Lancet 1992;340(8831):1317-9.

[12] Semprini AE, Macaluso M, Hollander L, Vucetich A, Duerr A, Mor G, et al. Safe conception for HIV-discordant couples: insemination with processed semen from the HIV-infected partner. Am J Obstet Gynecol 2013;208(5):402.e1-9.

[13] Ohl J, Partisani M, Wittemer C, Schmitt MP, Cranz C, Stoll-Keller F, et al. Assisted reproduction techniques for HIV serodiscordant couples: 18 months of experience. Hum Reprod 2003;18(6):1244-9.

[14] Sauer MV, Wang JG, Nataki CD, Nakhuda GS, Vardhan P, Jovanovic V, et al. Providing fertility care to men seropositive for human immunodeficiency virus: reviewing 10 years of experience and 420 consecutive cycles of in vitro fertilization and intracytoplasmic sperm injection. Fertil Steril 2009;91(6):2455-60.

15] Sauer M, Chang P. Establishing a clinical program for human immunodeficiency virus 1-seropositive men to father seronegative children by means of in vitro fertilization with intracytoplasmic sperm injection. Am J Obstet Gynecol 2002;186(4):627-33.

[16] Mmeje O, Cohen CR, Murage A, Ong'ech J, Kiarie J, van der Poel S. Promoting reproductive options for HIV-affected couples in sub-Saharan Africa. BJOG 2014in press.

\title{
Blood salvage device for use during ruptured ectopic pregnancy in low-resource countries
}

\author{
Caitlin O. Winget ${ }^{\mathrm{a}}$, Theresa K. Fisher ${ }^{\mathrm{b}}$, Rajen N. Kumar ${ }^{\mathrm{b}}$, Alexander H. Harrington ${ }^{\mathrm{c}}$, Gillian E. Henker ${ }^{\mathrm{b}}$, \\ Robertson D. Davenport ${ }^{\mathrm{d}}$, Alexander T. Odoi ${ }^{\mathrm{e}}$, Kathleen H. Sienko a,b,*
}

${ }^{a}$ Department of Biomedical Engineering, University of Michigan, Ann Arbor, MI, USA

${ }^{\mathrm{b}}$ Department of Mechanical Engineering, University of Michigan, Ann Arbor, MI, USA

c Department of Sociology, University of Michigan, Ann Arbor, MI, USA

d Department of Pathology, University of Michigan, Ann Arbor, MI, USA

e Department of Obstetrics and Gynecology, Kwame Nkrumah University of Science and Technology, Kumasi, Ghana

\section{A R T I C L E I N F O}

\section{Article history:}

Received 14 April 2014

Received in revised form 19 July 2014

Accepted 17 September 2014

\section{Keywords:}

Blood salvage

Blood transfusion

Implementation engineering

Low-resource countries

Maternal health

Medical device design

Ruptured ectopic pregnancy

\footnotetext{
* Corresponding author at: University of Michigan, 2350 Hayward St., 2650 G.G. Brown, Ann Arbor, MI 48109, USA. Tel.: + 7346478249.
}

E-mail address: sienko@umich.edu (K.H. Sienko).
Obstetric hemorrhage, the leading cause of maternal mortality, accounts for up to $44 \%$ of maternal deaths in regions of West and East Sub-Saharan Africa; $26 \%$ of these deaths can be attributed to the paucity of donated blood available for emergency transfusions [1]. This situation complicates the efforts of clinicians to treat ruptured ectopic pregnancy, which is the largest contributor to mortality in the first trimester. Autotransfusion is a life-saving intraoperative blood salvage procedure that is routinely performed using automated blood salvage devices in high-income countries [2]. Such devices are inappropriate for low-income countries owing to their cost and complexity (i.e. difficult to maintain), among other factors [3]. Furthermore, effective manual blood salvage solutions including the soup ladle method [4] and the Tanguieta funnel [3] developed for use in low-income countries can be labor intensive and require numerous disposables.

Design ethnography studies including clinical observations and interviews were conducted primarily at Komofo Anokye Teaching 